\title{
Geometric patterns in egyptian architecture \& interior design
}

\author{
DOI: $10.21625 /$ archive.v1i1.140
}

\author{
Heba-Talla Hamdy Mahmoud ${ }^{1}$ \\ ${ }^{1}$ Lecturer of interior architecture Decor department Faculty of Fine Arts Mansoura University
}

\begin{abstract}
Keywords
Geomertric; Pattern ; Sample;

Aincent egyptian; coptic;

;Christian; Islamic; Project

; Contemporary; Craft.
\end{abstract}

\begin{abstract}
This study will examine the role of geometric patterns in selected examples of Egyptian architecture, interior architecture and art. Ancient Egyptian, Coptic, and Islamic periods are the selected historical ages from Egyptian heritage due to the abundance of different works and styles with geometric pattern characteristics during their periods. In addition to the historical periods, the study will demonstrate some selected models from Egyptian contemporary architecture and arts. These models include architectural projects, traditional craft products and artistic works with geometrical characteristics. The study aims, through the extracted information, to increase the awareness about the effective role of geometric patterns as an architectural and artistic capability and to clarify the degree of freedom, flexibility and functionality as an inherent feature through demonstrating the different practices, styles and materials.
\end{abstract}

\section{Introduction}

Geometric patterns are employed by architects, interior architects and fine art artists to create a wide range of designs including textiles, ceramics, metalwork, architectural elements, and manuscripts. It considers one of the main matching points between architecture and arts through providing a variety of shapes, forms, models and formulas. "The simple forms of the circle, square, and straight line are the basis of the patterns. These elements are combined, duplicated, interlaced, and arranged in intricate combinations. Most patterns are typically based on one of two types of grid, one composed of equilateral triangles, the other of squares. A third type of grid composed of hexagons in which one regular polygon is repeated to tile the plane" (Fukushima C, 2004). "Geometric proportions in architectural patterns represent a design language, as words do in a spoken language. They determine the frameworks within which elements are arranged into a pattern, a relation between one element and another, and a proportional relation within one element. They address and reflect the natural laws that govern the basic harmonies of nature, being describable by means of mathematics and geometry" (Loai M, 2012). History indicates that the real origins of geometric patterns were found in ancient Egyptian, Chinese, Indian and Greek architecture and arts. Geometric patterns are a common factor in the majority of historical and contemporary architectural and artistic works. Remarkable features showing that in spite of the religious variations between Islam and Christianity, there are many common features in Egyptian society with the same realization and taste in the areas which geometrical patterns work.

\section{Research Methodology}

The methodology of this research mainly used a qualitative method based on descriptive approaches including primary surveys and historical tracing of the existence and usage of geometric patterns' works in Egyptian architecture, interior architecture and arts. The research classified the information into two categories, the first classification is based on the chronological series of time for the Egyptian historical selected periods. The Second 
classification is based on the usage of geometric patterns within each period and how these architectural heritages applied through the time of each period. Data and information collected through multiple refereed sources include books, journals, conferences, and specific official internet sites. More than one source for each element was used to confirm the integrity and consistency of the research.

\section{Geometric Patterns in Anicent Egyptian Architecture and Arts}

The great pyramid of Khufu with its sloping façade and other similar geometrical designs of ancient Egyptian artifacts such as Sakkara pyramid are explicit works of ancient Egyptian geometrical skills that demonstrate their proficiency in applying this field. There are many examples of geometrical designs that still exist until today in ancient Egyptian temples, walls, columns, ceilings and many other tools and objects refer to the extensive usage of Geometric patterns during ancient Egyptian periods. These ancient patterns gave birth to many historical and recent geometrical decorations, motifs and illustrations. "We can see a source for most of our familiar elements of design in the decoration which was used in Egypt long before any example that is known to us outside of that land. We are logically bound to look at the origin of these motives. If, then, we seek the source of most of the various elements of the decoration which covers our walls, our floors, our dishes, our book-covers, and even our railway stations, we must begin by studying Egypt. As our object is the history and evolution of the various elements of decoration, we may classify these elements. There is the simplest geometrical ornament of lines, spirals and curves, and of surfaces divided squares and circles" (Petrie WM, 1920). These patterns were applied using several materials like wood, marble, rugs, and clay with different styles such as zigzag, chess and other orders and formations. These major geometrical pattern types are found in furniture, ceilings, walls, and pottery. "In the furniture of ancient Egyptians, cubism and geometric shapes were the most distinctive characteristics. For the design of the cocktail cupboard, which was fashionable during this period, geometric and cubic lines were dominant. Besides the rectangular, linear, circular or triangular motifs, zigzag and stylized flowers, lines were expanding from the center as the sunlight that constitutes the main features of the designs and they carry influences from the Egyptian art. Cubic volumes and geometrical appearances are the primary outstanding characteristics in armchairs" (Sadikoglu P, 2007).

\section{Samples from Ancient Egyptian Geometric Patterns}

- Clay geometric patterns works

During the early times of the predynastic period in Egyptian history and along the ancient Egyptian dynasties, Egyptians used geometric patterns on their works especially in clay works like potteries, vases and bowls, Figure 4-1, Figure 4-2 present these styles of work that appear with clear, simple lines, and shapes and are very easy to recognize. "The systematic clearing of the Eighteenth Dynasty funerary pits and Ramesside tombs has brought to light some objects of exceptional quality and historical interest. These include pottery with geometric designs, for example Prince Baki's vase" (Corzo M, 1993).

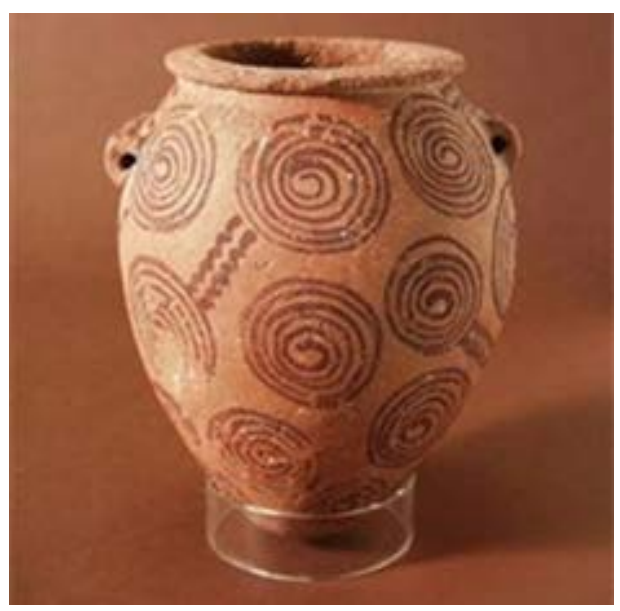

Figure 4-1: Pottery, Predynastic period

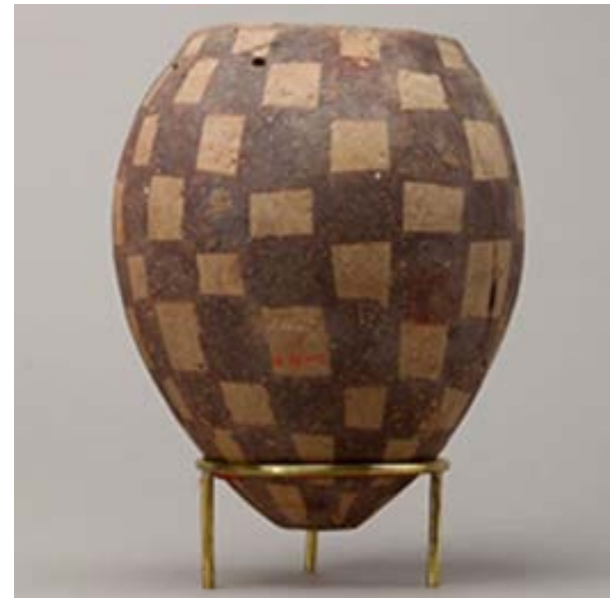

Figure 4-2: Pottery, Predynastic period

- Gaming boards with geometric patterns design

Gaming boards with geometrical designs were found in both the predynastic period and the first dynasty with different features according to the rules of gaming with several illustrations and colors. Figure 4-3 shows a gaming disk found in the tomb of chancellor Hemaka at Saqqara during the predynastic period (2935-2975 B.C), Figure 
4-4 board game, New Kingdom (1550-1077 B.C) "More Than 5,000 Years ago, the ancient Egyptians Invented a board game almost as elaborate as anything from Parker Brothers today. Beginning Simply as a form of recreation, this game was to evolve into a profound ritual, a drama for ultimate stakes. Called Senet or "passing," The game was based on the movement of draughtsman across a board consisting of 30 Squares arranged into three parallel rows of ten squares". (Peter A, 1980).

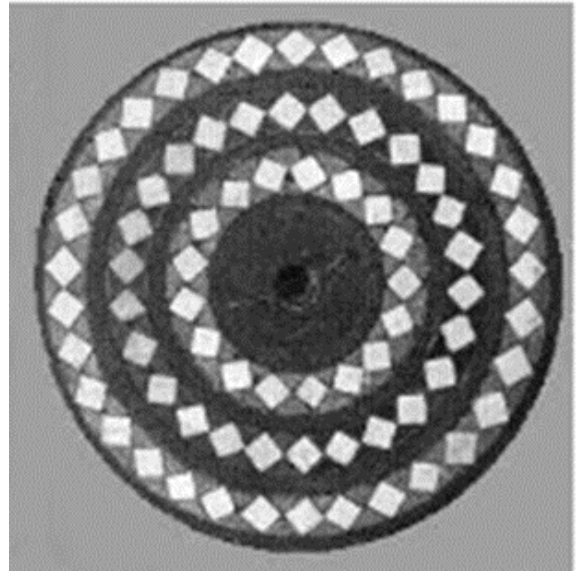

Figure 4-3 Gaming disk, Predynastic Period.

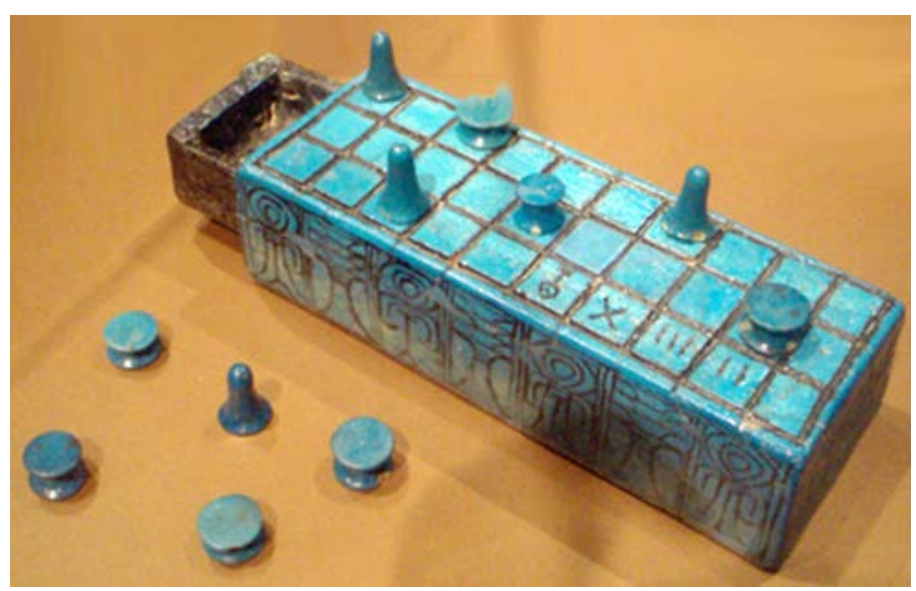

Figure 4-4 Board game, New Kingdom

- Kha's protractor, rose of direction and coffin

A unique style of geometric patterns employment at the time of king Amenhotep is the protractor of the architect $\mathrm{kha}^{1}$, which was discovered in his tomb in 1906, at Deir el-Medina in Egypt near the Valley of the Kings. "Note that the modern tool has the same shape as the object found in the Kha's tomb. To conclude this discussion, let me propose a comparison of the decoration of this Egyptian item with that of a compass rose of directions. We can go back from the compass rose to the Kha's rose, with small adjustments. Perhaps the origin of the design of the compass rose is in the ancient Egyptian tools" (Slyke V, 1991). Figure 4-5 introduces a comparison between contemporary compass rose of directions and Kha's rose of direction. This protractor is considered one of the pioneer devices for angles measurement. Figure 4-6, demonstrates this device as it is in Torino Egyptian museum. Other examples that belong to Kha with geometric patterns designs are Kha's rose of direction Figure 47 and Kha's coffin Figure 4-8.

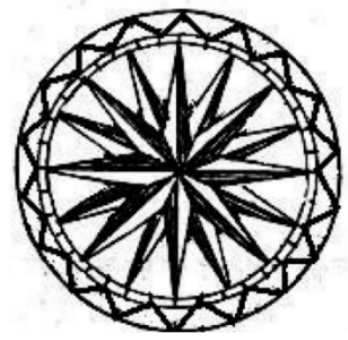

Figure4-5 Comparison between contemporary compass and Kha's protractor.

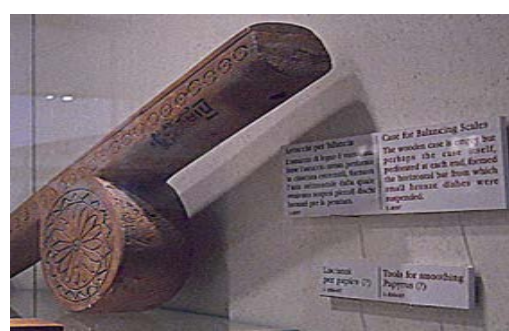

Figure4-6 Kha's protractor, 18th Dynasty.

\footnotetext{
${ }^{1}$ Kha: one of the most important supervisor and architect, responsible for some projects completed during the periods of three kings, Amenhotep II, Thutmose IV and Amenhotep III.
} 


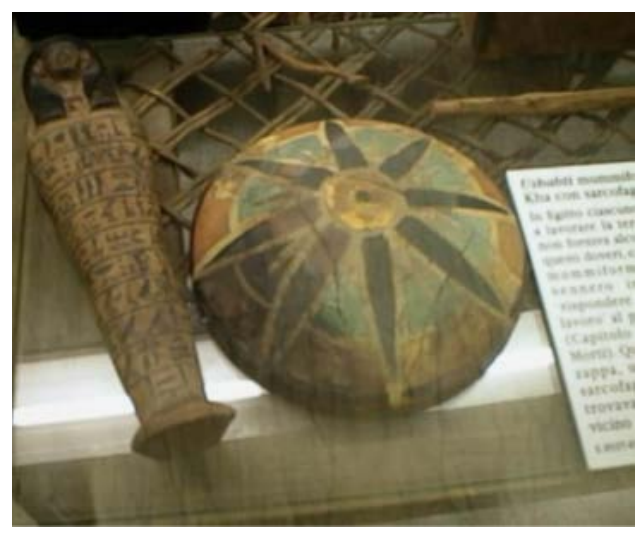

Figure4-7 Kha's rose of direction

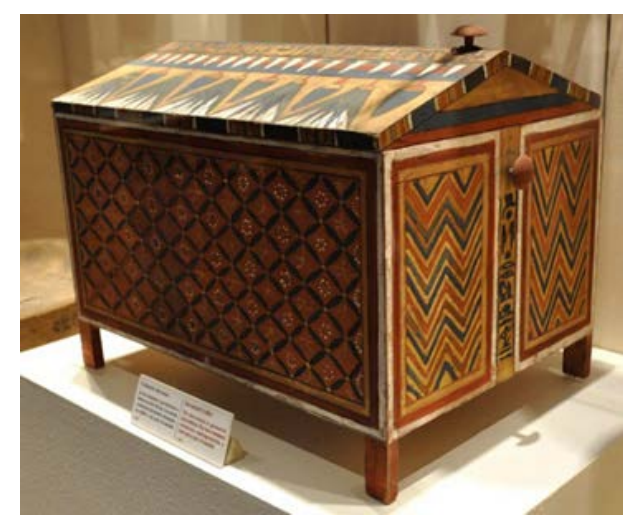

Figure4-8 Kha's coffin

- Ceiling paintings at amenhotep III palace

"Neferhotep, who lived during the reign of Haremhab, had the pattern above in his tomb chapel. The pattern incorporates his name and title with geometric and vegetal forms, like the spiral and blue lotus. Below, this pattern, which no longer exists, was copied from a neighboring tomb in Thebes. The pattern uses the winged scarab with a sun disc, symbolizing rebirth after death. During the New Kingdom, in the reign of Amenophis III. Thick cushions, covered with fabric in geometrical patterns, were placed on the chairs and footstools" (Olaf EK, 2000). Several geometrical patterns found in different room ceilings at the site palace of Amenhotep at malqata, the west bank of the nile at thebes, upper egypt, in the desert south of habu. Figure 4-9, Figure 4-10 and Figure 4-11 are three samples of geometric patterns of room ceilings at Amenhotep palace.

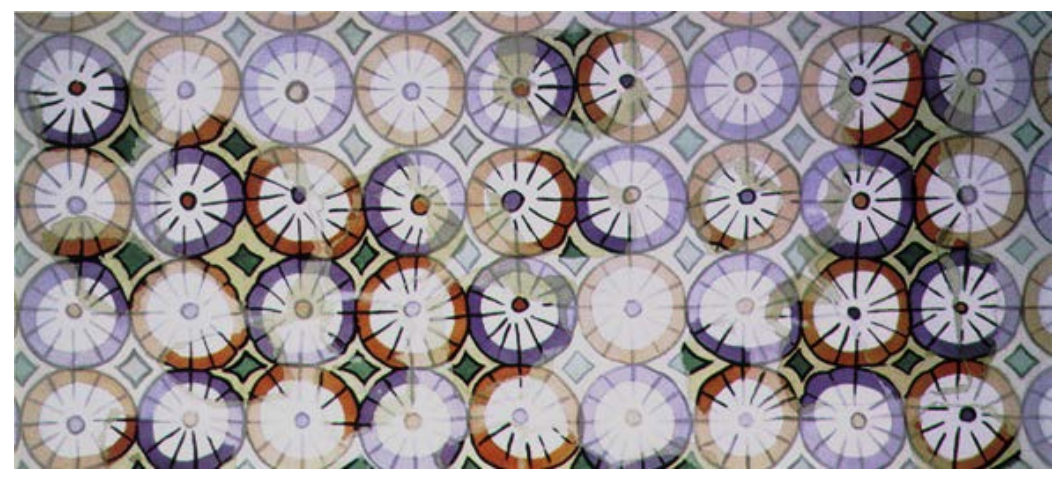

Figure4-9 ceiling Room L5, Amenhotep III palace.

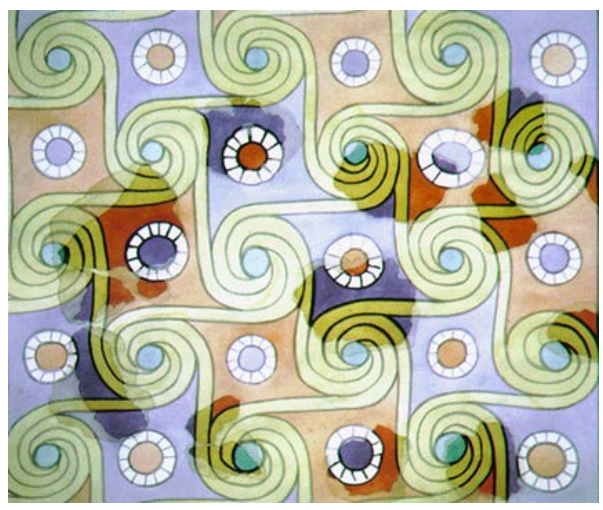

Figure 4-10 ceiling, Room N5 Amenhotep III palace.

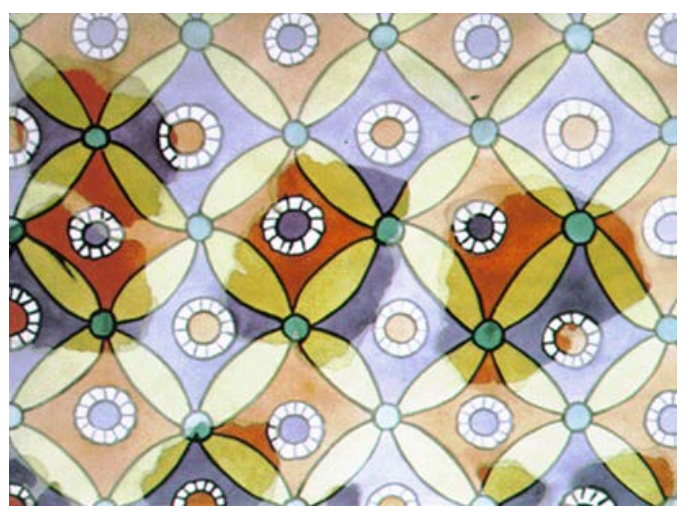

Figure 4-11 ceiling, Room B5 Amenhotep III palace.

\section{Geometric patterns in egyptian coptic architecture and arts}

In spite of the various designs of Coptic architecture and art with geometric patterns, the design that depends on the Cross as a focal element in the center of the work surrounded with fine ordered geometric shapes is the most common design. Geometric patterns are common between Coptic and Islamic art "It was not surprising to find-out that these came from the church despite their Islamic appearance. The idea of mixing crosses with eight pointed stars was very common and it reflected how artists saw the two religions as being strongly connected. This particular design appeared quite often and is still used today in Egypt to express the unity of religions. It's seen on 
public buildings in Egypt like on the doors of the main entrance to the Palace of Arts in Cairo" (El-Akkad T, 2013). One of twenty panels with geometrical decorations that was discovered by archaeologists belongs to the period within the 6th century $\mathrm{AD}$ and the 7th century $\mathrm{AD}$ which was presented at Coptic museum in Cairo, Figure 6-1. The Coptic marble works are distinguished with their high level of accuracy and professionalism, Figure 6-2 shows a marble water fountain in the Coptic Museum. Many Bookbinding covers are decorated with historical geometric patterns such as Gospels from the Monastery of Holy Mary Mother of God at Perkethoout in Fayum during the period within 7th century and 7th century AD which was purchased by Pierpont Morgan in 1911, located now in the museum of Morgan library in New York, Figure 6-3. The stained glass with geometric pattern decorations in attractive colors is a demonstrative type of Coptic geometric patterns, Figure 6-4 shows a glass window in the hanging church in Cairo. The woodworks of the hanging church in Cairo are known for the accurate geometric pattern works, Figure 6-5, Figure 6-6. Coptic textiles are distinguished with their antique shape, Figure 6-7 is an example of this type of art in the Coptic museum in Cairo.

\section{Samples from egyptian coptic geometric patterns}

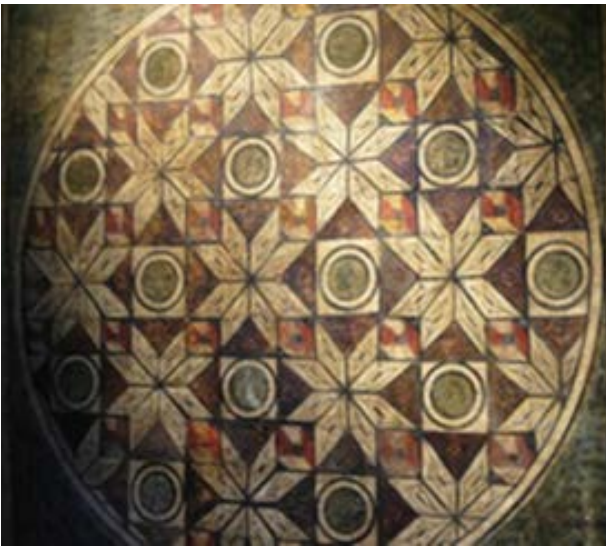

Figure 6-1 panels, Coptic museum

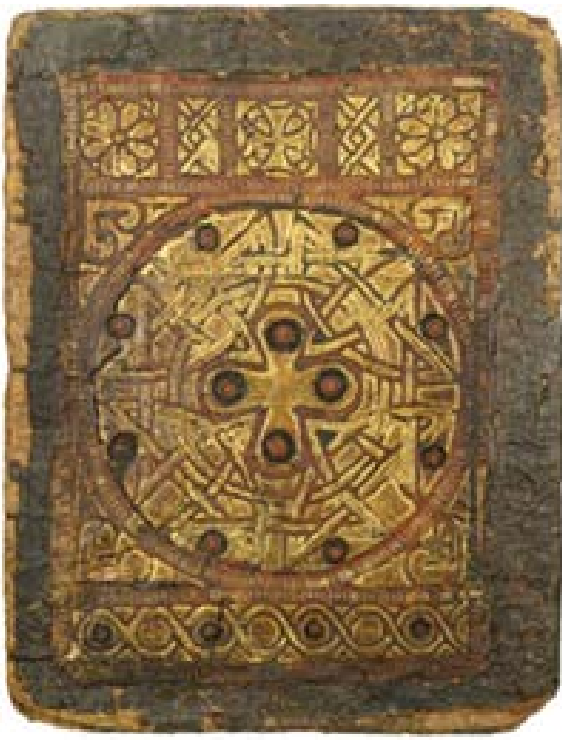

Figure 6-3 bookbinding of Holy Mary

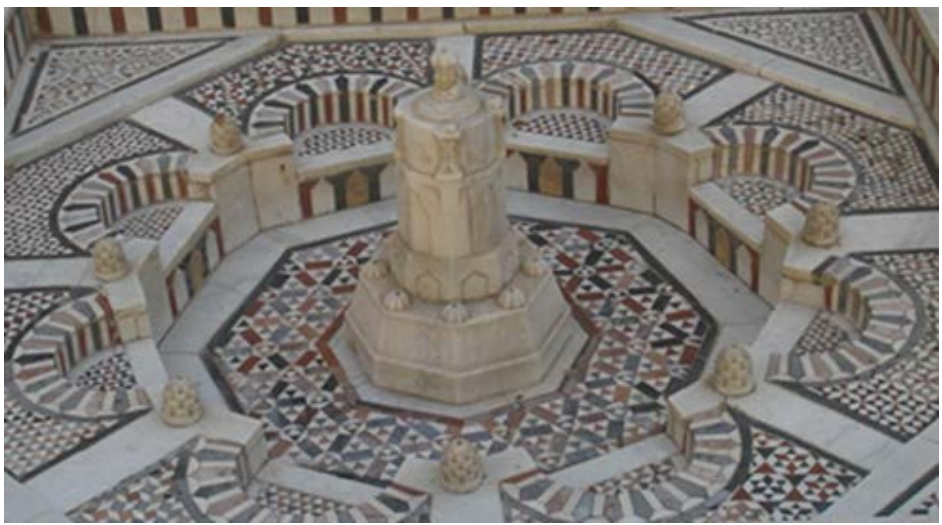

Figure 6-2 water fountain, marble work, Coptic Museum

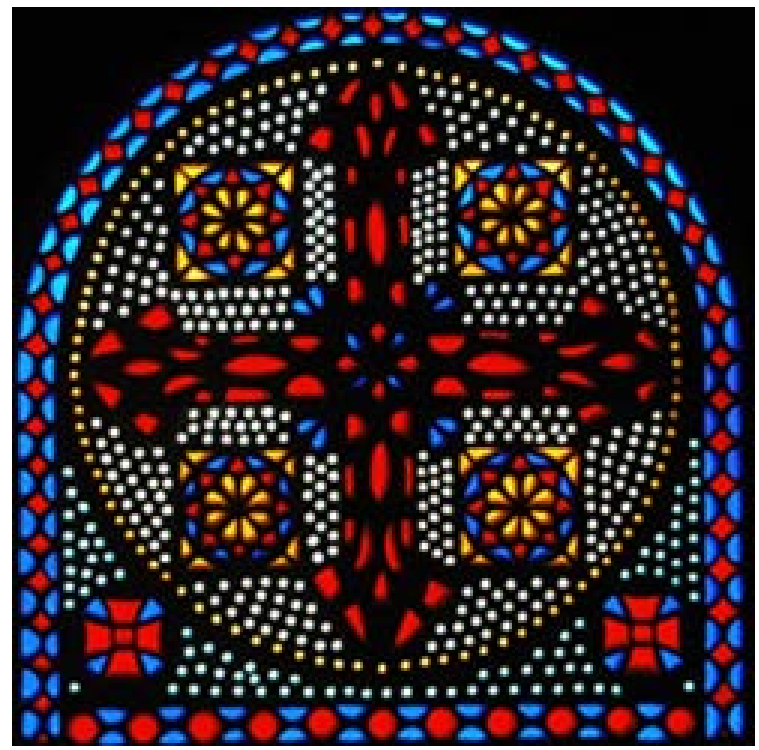

Figure 6-4 stained glass, hanging church 


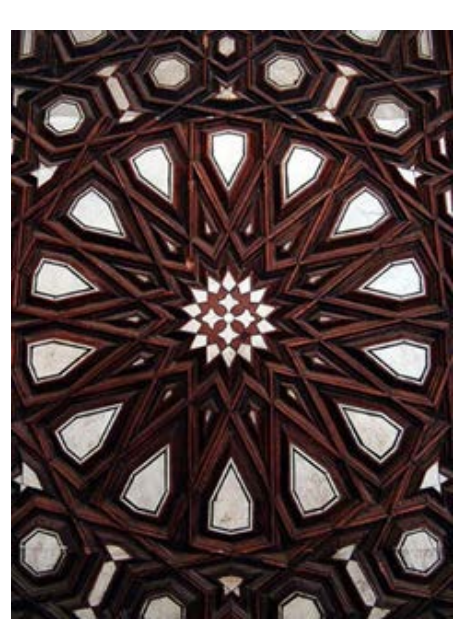

Figure 6-5 Woodworks, Hanging Church. Figure 6-6 Woodworks Hanging Church.

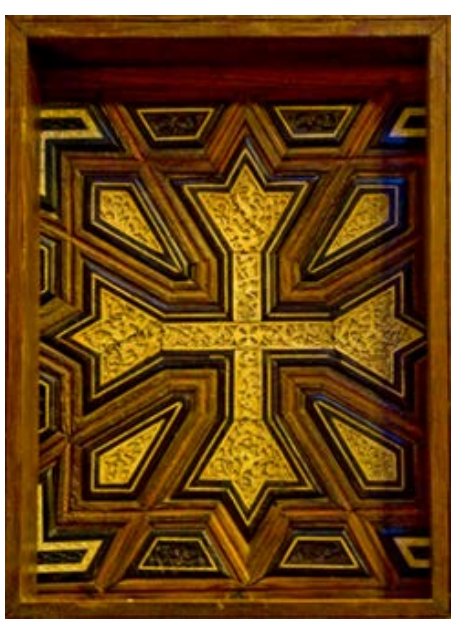

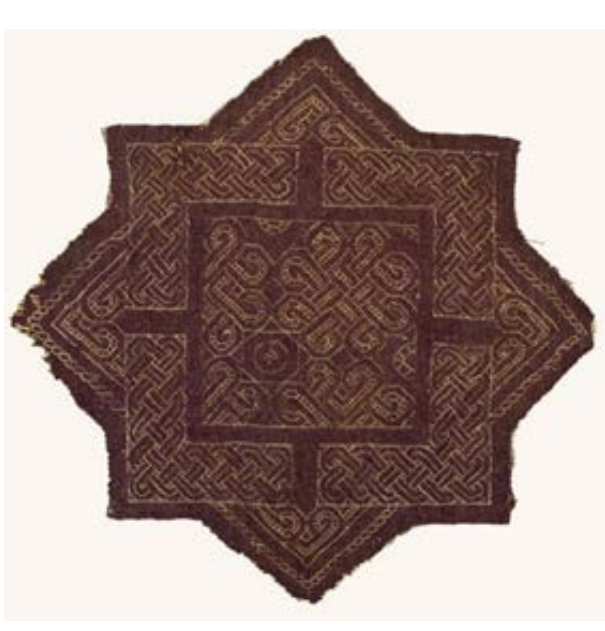

Figure6-7 Coptic museum

\title{
7. Geometric patterns in egyptian islamic architecture and arts
}

A quick survey of Egyptian Islamic construction with its entire mosques, mausoleums, domes, minarets, minbars, walls, floors, ceilings, doors, windows, pots, lamps, book covers or textiles makes it easy to discover the impact of geometric patterns in different styles and shapes. "Original stucco panels with vegetal motifs and window screens with geometric designs are surviving in Al-Azhar Mosque. Stuccoworks above the windows and over the walls with abstract 6-point geometrical design added during Caliph al- Hafiz. There is another Mihrab with significant geometrical decorations. The most significant surviving element of Al-Juyushi Mosque is the lavish carved stucco of its Mihrab with floral and geometrical patterns. There are abstract six-point geometrical patterns over the spandrel of the Mihrab. The interior apex of the dome is also designed with a six-point star with Arabic inscriptions. One of the earliest types of Islamic geometrical patterns is the six-point geometrical pattern, which has been used in square and can be found in Ibn-Tulun mosque in Cairo” (Embi MR, 2012). These patterns are characterized with remarkable spaces of freedom and variety and also have the capability of growth and extension with repetition and complexity. Egyptian Islamic geometric patterns have the ability to accommodate and be incorporated within other types of ornamentation. Calligraphic, arabesque, and nature element patterns are clear forms of that interaction. "Geometric ornamentation in Islamic art suggests that complex arrangements and combinations of elements are infinitely expandable; the frame surrounding a pattern appears to be arbitrary and the basic arrangement sometimes provides a unit from which the rest of the design can be both predicted and projected" (Fukushima C, 2004). This evolution of Egyptian geometric patterns is due to the Egyptian worker's cleverness, skills, and innovation besides the role of social and cultural characteristics of Egyptian crafts. "The large window in the middle of the Sultan Qalawun complex has incomplete large geometric-rosettes emanating from eight-pointed stars. The two smaller windows on either side have stucco grilles of four stacked large geometric-rosettes emanating from six-pointed stars filling the whole window" (El-Akkad T, 2013). Islamic geometric patterns styles of Egyptian works are produced using various materials. The most famous products are designed in wood, specially inlaid woodwork of doors, minbars and Mashrabeya, Figure 8-1, Figure 8-2 are two samples of woodwork. Stonework with large scale and simple forms are clearly presented in Islamic building fronts, minarets, domes, and entrances, Figure 8-3, Figure 8-4, and Figure 8-5. Metal works are known to be proficient and accurate, Figure7-7, Figure7-8. Marble geometric designs with their rich color spectrum take remarkable proportion especially in floor surfaces, Figure 8-9 Figure 8-10. Egyptian Islamic geometric patterns exist in several other materials such as stained glass, colored glazed brickwork, ceramic mosaic, stucco works and book illumination.

\section{Samples from Egyptian Islamic Geometric Patterns}

\author{
- Islamic geometric patterns, woodwork
}




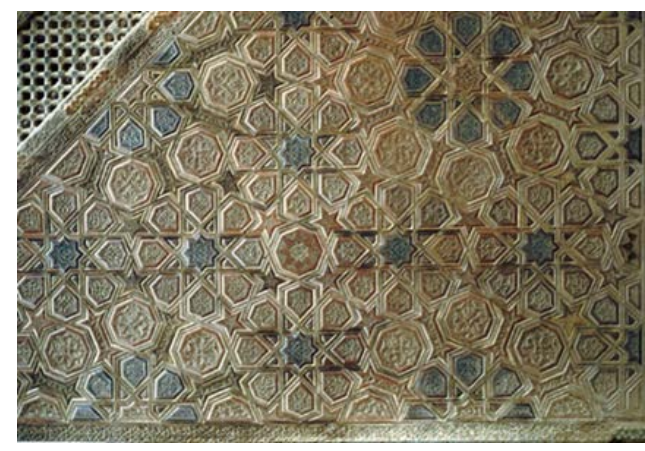

Figure 8-1 Ibn Tulun mosque; minbar, woodwork

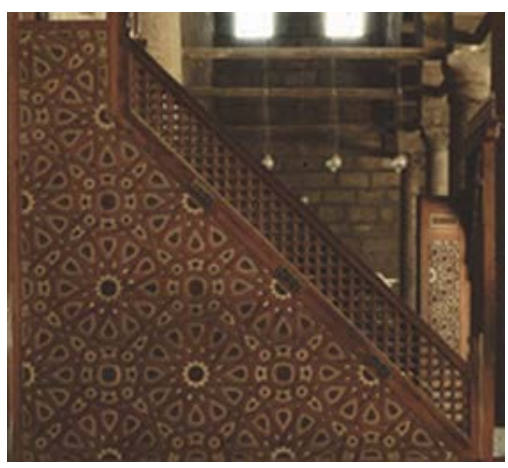

Figure 8-2 Al-Nasir mosque minbar, woodwork

- Islamic geometric patterns stonework

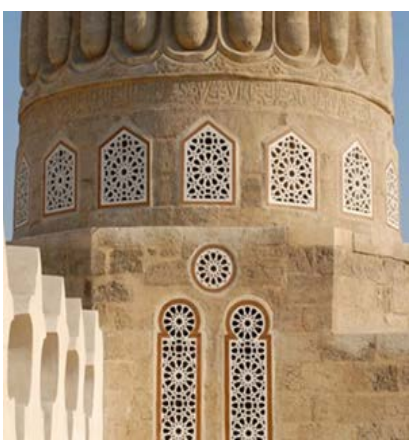

Figure 8-3 Madrasa umm al-sultan sha'ban.

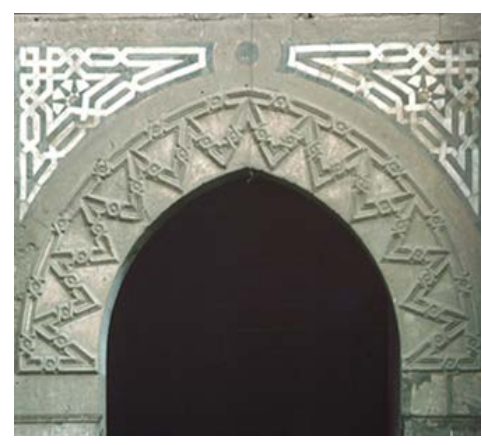

Figure 8-4 Madrasa umm al-sultan sha'ban

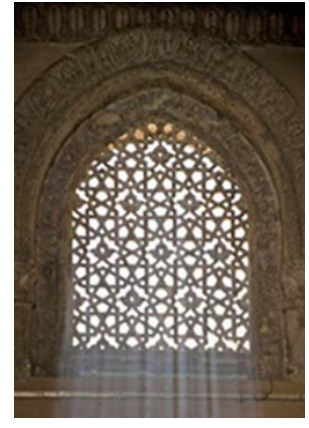

Figure 8-5 Ibn tulun mosque

- Islamic geometric patterns metal sample

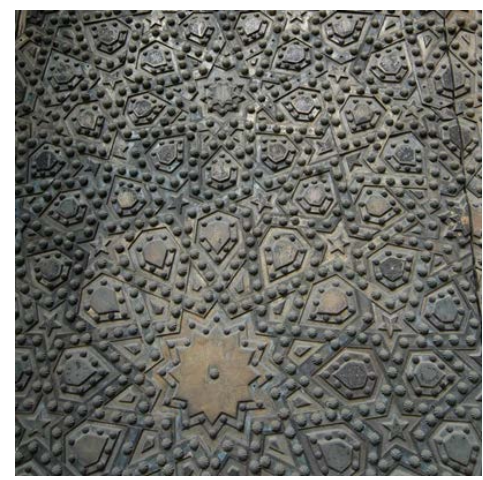

Figure 8-7 bronze door, Sultan hassan mosque.

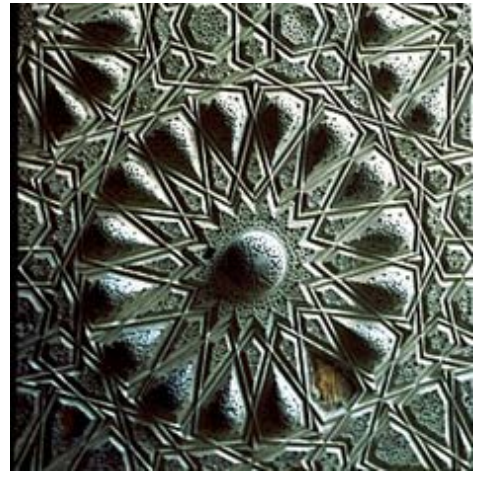

Figure 8-8 bronze door, al-Mu'ayyad Mosque

- Islamic geometric patterns marbel sample

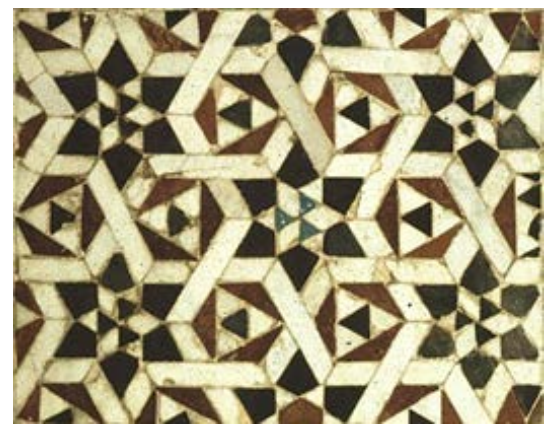

Figure 8-9 al-Maridani Mosque marbel work

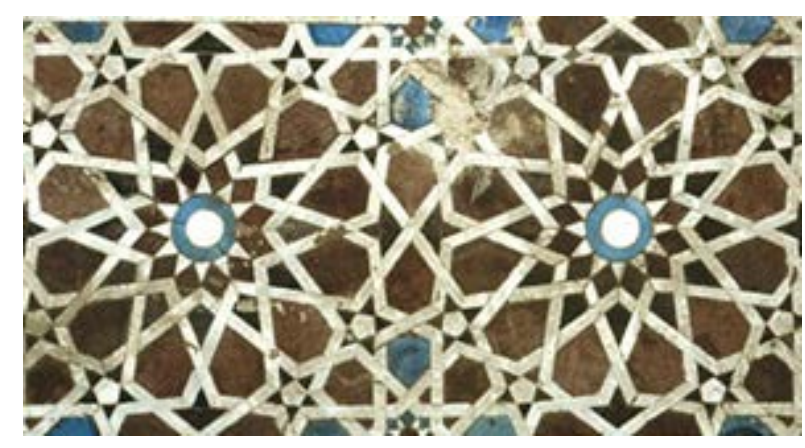

Figure8-10 al-Maridani Mosque marbel work 


\section{Geometric Patterns in Egyptian Traditional Architecture}

The traditional residential construction of mamluk and ottoman periods with their architectural and interior features provide additional confirmations about the proficient and extensive use of geometrical patterns in Egyptian culture. Bayt el Suhaymi is a remarkable example of Egyptian residential traditional buildings with geometrical decorations, the geometrically carved wooden dome with its graceful lantern displays traditional Arabesque patterns, Figure 9-1. There are also the smaller domes with geometrically cut colored glass that appear like jewel, Figure 9-2, windows on the upper floors besides those in the halls and rooms covered with colored glass, Figure 9-3, and the Ceiling is decorated with many shapes of geometric patterns, Figure 9-4, these are some explicit examples from Bayt el Suhaymi. Al Sinnari house presents other clear examples of these traditional sites that have many geometric patterns works. "The entrance block façade consists of two intertwining arches. The frame of the outer arch etched in zigzag shapes and geometrical decorations, surrounded by with hexagonal decoration, above which there is a circular ornament at the center of the arch. The doorframe is surrounded with geometrical decorations on stone. Both sides of the door and the entrance façade are decorated with geometrical decorations in round square and rectangular shapes, Figure 9-5. The ceiling has been decorated with wooden boards made of square- and rectangular-shaped geometrical forms and rosettes" (Mahmoud, 2014). Khan el-khalili district, AlSayeda Zeinab District, Al Moezz Street, Ghouriyya complex are examples of Egyptian zones and buildings that have wide varieties of geometric pattern designs.

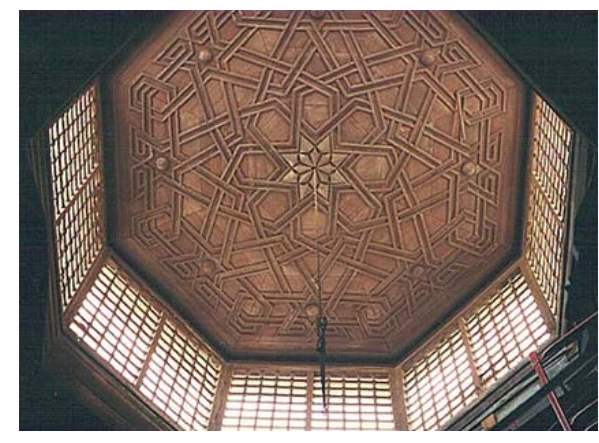

Figure 9-1 wooden dome of Bayt el Suhaymi

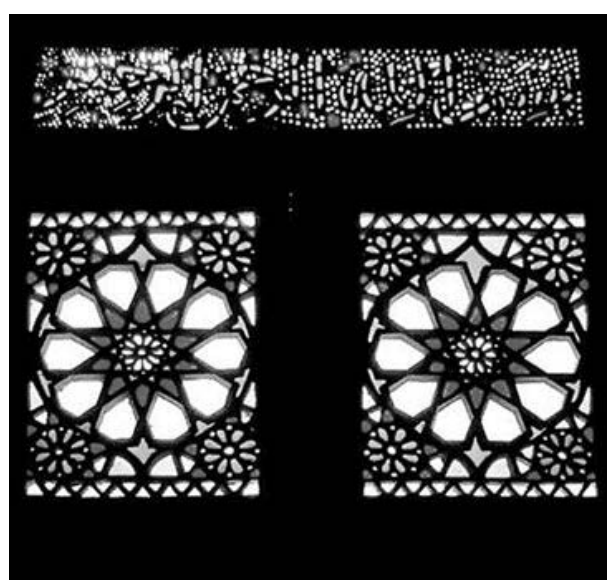

Figure 9-3 windows of Bayt el Suhaymi

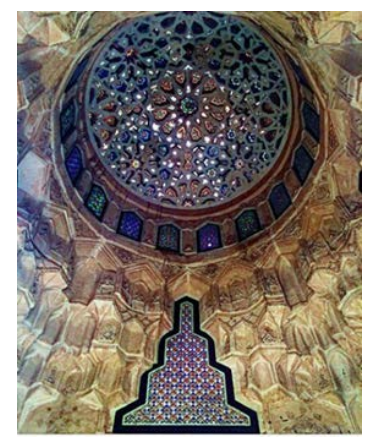

Figure 9-2 Colored glass dome of Bayt el Suhaymi

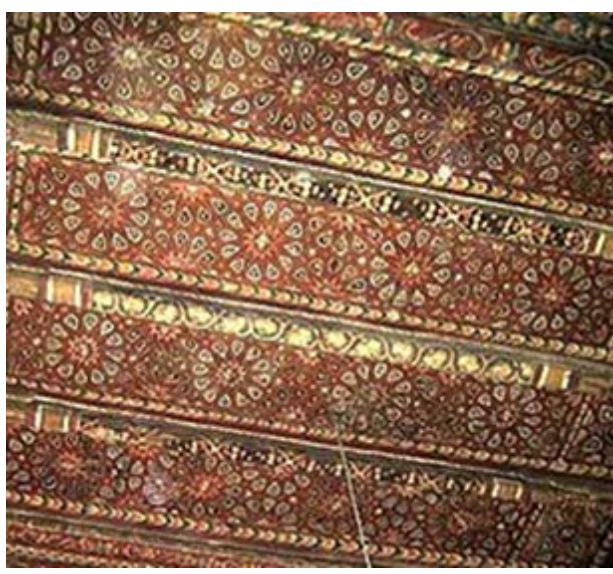

Figure 9-4 ceiling of Bayt el Suhaymi

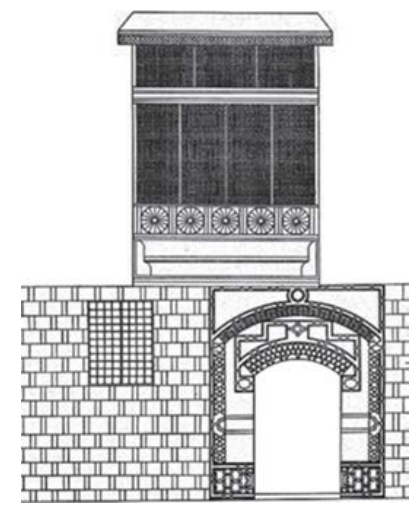

Figure 9-5 The front of al Sinnari house 


\section{Geometric Pattern in egyptian Contemporary projects}

Although the fundmental elements of historical Islamic architecture were designed and built to respond effectively and dynamically to people's physical, environmental, social, physiological and religious requirements in the past, it can also be successfully implemented in current and future architectural and interior designs. Islamic goemetric patterns is one of the practical usage of this concept. There are many evidences in Egyption contemporary architecture projects specially in the domain of interior architecture and decoration. The design of both The National Cultural Center (Cairo Opera House) Figure 10-1 and the American University in Cairo (new campus) Figure 10-2, are two examples for the successful usage of islamic architecture with modern methodologies.

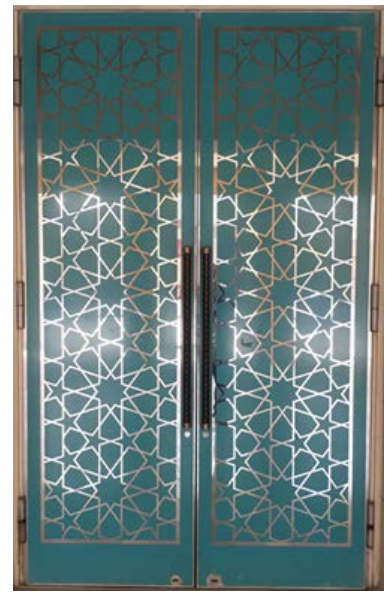

Figure 10-1 Cairo opera house

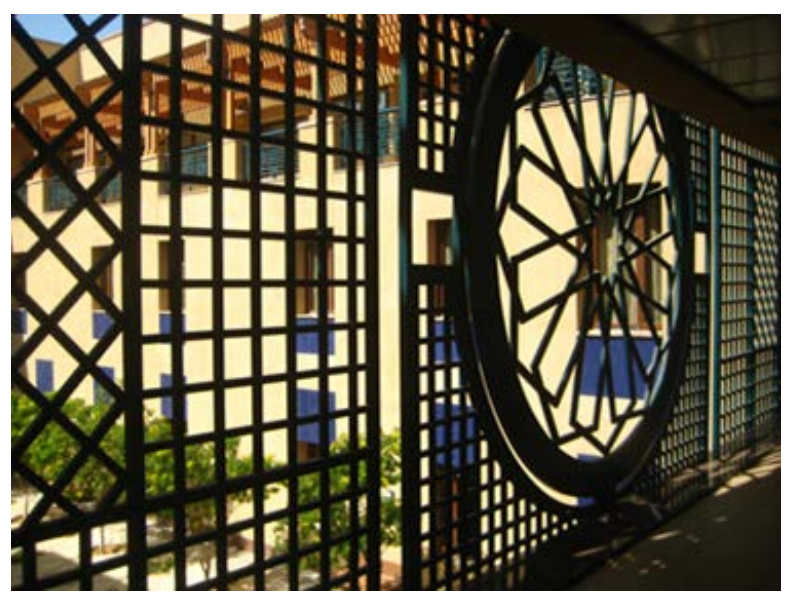

Figure 10-2 AUC new campus

\section{Geometric patterns in Egyptian traditional crafts}

One of the main reasons that made geometric patterns widely spread in the Egyptian artistic and architectural domain is its major usage in most Egyptian traditional crafts. Gifts, pottery, textiles, copper works, handmade jewelry, wood works and ceramics are some famous examples that are designed using geometric shapes. Egyptian traditional crafts markets such as Khan El-Khalili and Al Fustat zones consider open exhibitions with numerous variety of traditional crafts and gifts based on geometric pattern designs. Al Fustat traditional crafts and ceramics produce many products that are based on geometric patterns design. Figure 11-1, Figure 11-2. Are two examples of that.

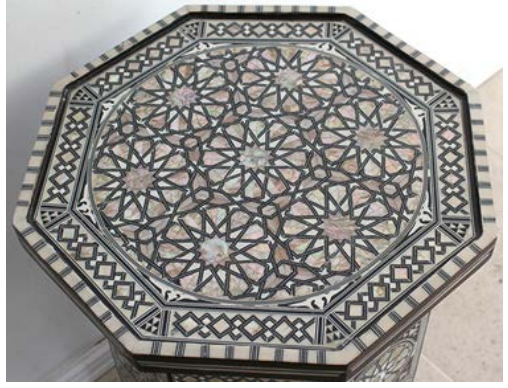

Figure 11-1 traditional geometric patterns

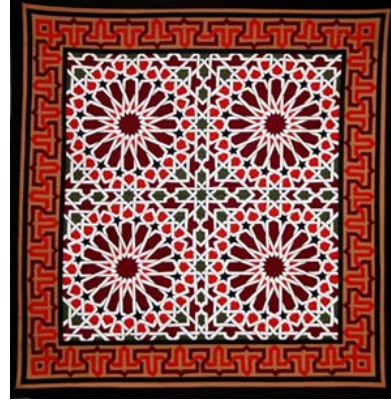

Figure 11-2 traditional geometric patterns

\section{Geometric Patterns in Egyptian Artists Works}

\section{- Ahmed Mostafa’s works}

Ahmed Mustafa is an Egyptian artist who specializes in Arabic arts. He created rich visual art works through his innovative mixture of painting and Calligraphy. Many of his art works include geometrical patterns. "Ahmed Moustafa (1943-) is a perfect example. Many of Moustafa’s works present Koranic verses in three- dimensional forms, and at times he juxtaposes two different traditional scripts-in Still Life of Quranic Solids, he uses geometric Kufic for the background and cursive Thuluth for the three- dimensional shapes" ( Shabout N, 2010). Figure 12-1, Figure 12-2 are samples of Ahmed Mustafa's painting with geometric patterns. 


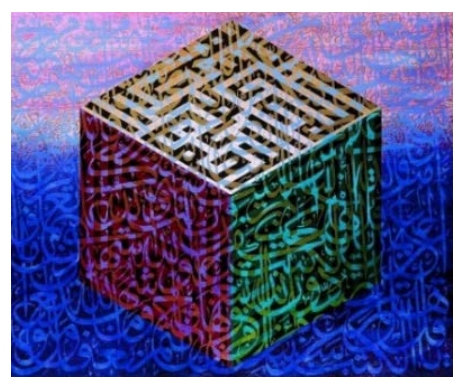

Figure 12-1Ahmed Mustafa’s painting

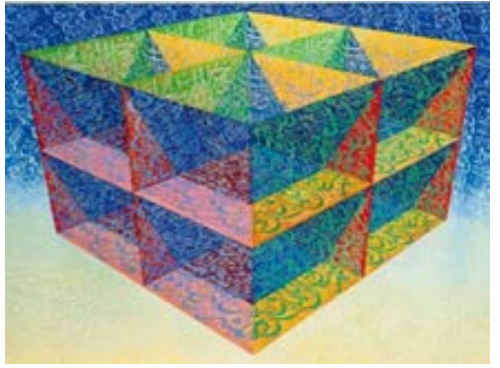

Figure 12-1Ahmed Mustafa’s painting

\section{- Abdel Rahman El Nashar’s works}

Abdel Rahman El Nachar, born in 1923 and died in 1999, obtained his PhD in 1978 from the Budapest Art Academy. He participated in numerous exhibitions and was awarded the 1st prize in painting at the Cairo Salon, and later the 1st prize of the 4th Biennale in 1992. In the early stages of his artistic career, most of his art works style were a combination of both expressionism and surrealism. During the last 10 years of his artistic life, most of his works were subjected to geometric pattern abstraction art, Figure 12-3, Figure12-4 are samples of El Nashar's painting with geometric patterns.

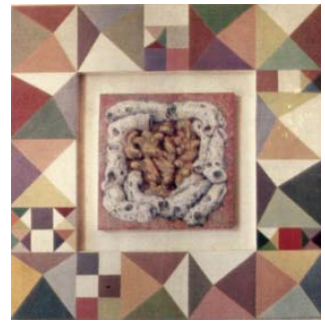

Figure 12-3 El Nashar painting

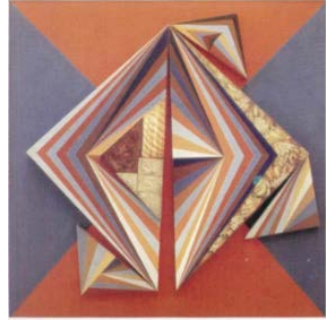

Figure 12-4 El Nashar painting

\section{Conclusion}

Egyptian architecture, interior architecture and arts give geometric patterns a great deal of importance and respect. The employment of geometrical patterns in the Egyptian environment that are designed in various materials such as, wood, marble, clay, glass, stone, metal and textile. It has many different sizes, volumes and scales, scales from tiny and precise works such as handmade jewelry to the huge surface of great pyramid and massive domes of main mosques. Egyptian geometrical patterns are spread all over the country in most cities and districts. The existence of geometrical pattern works is a continuous and essential portion of Egyptian architecture, interior architecture and arts across the history of Egypt from the ancient Egyptian era up to contemporary time. The heritage of previous historical periods, in particular the Coptic and Islamic periods, are filled with architectural and art works with pure geometrical pattern designs or in coordination and consistency with other styles of ornamentations using calligraphic, arabesque and the nature element. The role of Egyptian workers and craftsman skills has an impact on the proficiency of Egyptian geometrical patterns. The usage of Egyptian geometrical patterns engages with the people's religious, residential and cultural features.

\section{References}

1. Petrie, W. M. Flinders 1853-1942. (1920). Egyptian decorative art. 2d ed. London: Methuen \& co.

2. Hopkins, H. P. (1886 - 1959). Henry Powell Hopkins papers.

3. Museum of Fine Arts, Boston \& Smith, William Stevenson (1960). Ancient Egypt as represented in the Museum of Fine Arts, Boston (6th ed., fully rev). The Museum, Boston.

4. David WD., (1976), Pattern in Islamic Art. 1st.ed. Vista: Overlook Press and Studio.

5. Strunk Jr W, White EB. (1976), The elements of style. 3rd ed. New York: Macmillan.

6. CORZO, M. A., \& AFSHAR, M. (1986 - 1992). Art and Entertainment[PDF]. The Getty Conservation Institute.

7. Killen, G. (1994). Egyptian WoodVITorking and Furniture[PDF]. British Library Cataloguing in Publication Data.

8. Bard, K. A. (2005). Encyclopedia of the Archaeology of Ancient Egypt. Routledge, Taylor \& Francis Group. 
9. D’Avennes , E. P. (2007). Islamic Art in Cairo.

10. Pottmann, H., \& Bentley, D. (2007). Architectural geometry (1st ed.). Exton, Pa: Bentley Institute Press.

11. Fukushima C, Hens M, Turchinsky M. (2004), Islamic Art and Geometric Design. 1st ed. New York: Metropolitan Museum of Art.

12. Sarfraz M. Geometric Modeling Techniques, Application, System and Tools. 1st ed. Norwell: Kluwer publisher; 2004

13. Sadikoglu P. (2007), Ancient Egyptian Art. 1st.ed. Istanbul. Boyut Yavin Grubu.

14. Broug, E. (2008). Islamic geometric patterns. London: Thames \& Hudson.

15. Hessian M. (2010) Islamic Ceramics in Egypt. 1st ed. Cairo: Dar Ghareeb for Printing Pup. \&Dist.

16. El-Akkad T. (2013), The Aesthetics of Islamic Architecture \& the Exuberance of Mamluk Design. 1st ed Barcelona. University of Catalonia

17. Mahmoud AA. (2014), Al Sinnari houses. 1st ed. Alexandria: Bibliotheca Alexandria.

18. Piccione, P. A. (1980). In Search of the Meaning of Senet [PDF].

19. Hoskins, N. A. (1986). The Tapestries of Coptic Egypt[PDF]. ARS TEXTRINA.

20. Sehnaz CS, Cagdas G. (2007), A Shape Grammar Study:Form Generation with Geometric Islamic Patterns [PDF]. Istanbul: 10th Generative Art Conference GA.

21. Pottman, H., Asperl, A., Hofer, M., Kilian, A., \& Bentley, D. (2007). Architectural geometry (Vol. 724). Exton: Bentley Institute Press.

22. Shabout, N. M. (2010). The Arabic Connection in Articulating North African Modernity in Art. South Atlantic Quarterly, 109(3), 529-543.

24. Embi MR, Abdullahi Y. (2012), Evolution of Islamic Geometrical Patterns. GJAT Global Journal Al-Thaqafah.

25. Loai M. Geometric proportions: (2012), The underlying structure of design process for Islamic geometric patterns. Frontiers of Architectural Research: 1:P381.

26. Ramzy N. (2012), The impact of local environment aspects on Coptic architecture in Egypt. Alexandria University Engineering Journal: $51 ; 325-341$.

27. Behnam G, Atefeh F, Ali T. (2013), Symbols and Signs in Islamic Architecture. European Review of Artistic Studies: $4: 73$.

28. Sidawi B. (2013), Understanding the vocabulary of the Islamic architectural heritage. GBER Global Built Environment Review 8:26 39.

29. Doris B. (1989), Islamic Architecture of Cairo . 1st ed. Leiden: brill publishers.

30. Slyke V. (1991), Tools and Applications. 1st ed. New York: The Free Press.

31. Touny G. (1992), Hand Book of Islamic Ornament. 1st ed. Bern: Egyptian Documentation \&Information Center.

32. Olaf EK. (2000), Atlas of Egyptian Art. 2d ed. Cairo: The American University in Cairo Press 